\title{
CLINICAL AND DEMOGRAPHIC PROFILE OF PERSON WITH EPILEPSY IN TERTIARY CARE HOSPITAL OF BUNDELKHAND REGION, CENTRAL INDIA
}

\author{
Arvind Kankane ${ }^{1}$, Aradhana Kankane ${ }^{2}$
}

${ }_{1}^{1}$ Assistant Professor, Department of Neurology, MLB Medical College, Jhansi, Uttar Pradesh.

${ }^{2}$ Assistant Professor, Department of Paediatrics, MLB Medical College, Jhansi, Uttar Pradesh. ABSTRACT

\section{BACKROUND}

Epilepsy is one of the most common neurological disorders in the world. It is seen that relative frequency of various clinically important characteristics are different in persons with epilepsy (PWE) living in different geographical area. The purpose of this study is to determine the clinical and demographic profile of epilepsy in Bundelkhand region of central India.

\section{MATERIALS AND METHODS}

This is a descriptive study. All persons with epilepsy attending epilepsy clinic of neurology department were enrolled in this study. Detailed clinical history and general physical examination were carried out. CT scan head, EEG and other relevant investigations were done to determine cause and type of epilepsy. Antiepileptic drug therapy and compliance to treatment was also recorded.

\section{RESULTS}

One hundred and seventy six patients were included in this study. Mean age of onset were $17.4 \pm 10.4$ years. Two-third of persons were from poor socioeconomic strata and from rural background. Age of onset of epilepsy was less than 15 years in $44 \%$ patients. Ten percent of patients gave family history of epilepsy among first degree relatives. Most common seizure type was generalised tonic-clonic seizures (68\%). Sleep deprivation was the most common precipitating factor. Cause of seizure was idiopathic in $64 \%$ patients. Neurocysticercosis was found in $14 \%$ of patients and was the most common cause of secondary epilepsy. Eighty five percent were treated with single antiepileptic drug. Noncompliance for drug therapy was seen in $28 \%$ patients, which underscore the need for continuous and effective public awareness programme towards this condition.

\section{CONCLUSION}

Understanding of clinical and demographic profile of patients with epilepsy is needed to develop appropriate strategies for better and effective health planning.

\section{KEYWORDS}

Epilepsy, Bundelkhand, Clinical and Demographic Profile.

HOW TO CITE THIS ARTICLE: Kankane A, Kankane A. Clinical and demographic profile of person with epilepsy in tertiary care hospital of Bundelkhand region, Central India. J. Evolution Med. Dent. Sci. 2018;7(02):214-217, DOI: 10.14260/jemds/2018/48

\section{BACKGROUND}

Epilepsy is one of the most common neurological disorders in the world. According to World Health Organisation (WHO), more than 50 million people worldwide live with epilepsy and out of them $80 \%$ live in economically backward and developing country.(1) It is estimated that there are more than 10 million persons with epilepsy (PWE) in India. Its prevalence is about $1 \%$ in Indian population. The prevalence is higher in rural $(1.9 \%)$ as compared to urban population (0.6\%). Large numbers of PWE do not receive appropriate treatment for their condition, a phenomenon called treatment gap (TG). In India, the magnitude of epilepsy treatment gap range from $22 \%$ among urban middle income people to $90 \%$ in villages.(2) It is believed that relative frequency of various clinically important characteristics in PWE living in different geographical area would vary because of ethnic and cultural

'Financial or Other Competing Interest': None.

Submission 15-11-2017, Peer Review 24-12-2017,

Acceptance 29-12-2017, Published 08-01-2018.

Corresponding Author:

Dr. Arvind Kankane,

Department of Neurology,

MLB Medical College,

Jhansi, Uttar Pradesh, India.

E-mail: drarvind_neuro@rediffmail.com

DOI: $10.14260 /$ jemds $/ 2018 / 48$ differences. It is important to determine clinical profile of epilepsy in different human population to broaden available knowledge and to collect baseline data for cross-cultural comparison. It is important to understand clinical profile of epilepsy at tertiary level, so that appropriate intervention measures according to type of epilepsy and other issue may be addressed. In India, only few studies have been conducted in this regard. $(3,4)$ Bundelkhand is a geographic area of central India, which is divided between states of Uttar Pradesh and Madhya Pradesh. It has total population of about 18 million, out of which approximately 14 million live in rural area. This area is considered as economically backward and under developed area of central India. This region also has low level of health and educational system.(5,6) To the best of our knowledge, no study on epilepsy is conducted from this part of country. The aim of present study was to assess the clinical and demographic characteristics of a person with epilepsy in Bundelkhand region of central India. Finding of this study would be helpful in adapting strategies for better and effective health planning.

\section{MATERIALS AND METHODS}

This descriptive study was conducted in Maharani Laxmibai Medical College, Jhansi, Uttar Pradesh, India. This is the only tertiary care hospital in Bundelkhand region. Ethical clearance was obtained from Institutional Ethical Committee prior to start of study. All persons with epilepsy attending 
epilepsy clinic of neurology department during January 2016 to July 2016 were enrolled in this study. After getting informed consent, data were collected and recorded in semistructured proforma. Variables included data related to sociodemographic characters, age of onset of epilepsy, type of seizure and other clinical manifestations, associated cause, precipitating factors, associated comorbid conditions, received medications and compliance to treatment. All patients underwent electroencephalography (EEG) and computerised tomography (CT) scan of the brain. Socioeconomic status was determined by using the modified BG Prasad classification of 2004.(7) Type of seizures were classified according to ILAE 2010 guidelines.(8) For this study, compliance was defined as not missing a dose and noncompliance as missing a dose or stopping treatment in the last month.(9) The data was analysed and presented as categories and percentage.

\section{RESULTS}

A total of 176 persons were included in the study. 55\% were male and $45 \%$ were female. Mean age were $17.4 \pm 10.4$ years. Almost half of them (44\%) belonged to productive age group (15 - 45 yrs.) [Table 1]. Majority of them were from poor socioeconomic strata (77.2\%) [Figure 1], and from rural background (72.7\%). Twenty two percent of the subject were illiterate, while $42 \%$ were educated to the primary level. Age of onset of epilepsy was less than 15 years in about half (44\%) of patients, of whom $21 \%$ developed within 5 years of age [Table 2]. Ten percent of patients gave family history of epilepsy among first-degree relatives. Mean duration of seizures was 5.8 years and mean number of episode was 4.5 per year. Forty percent of patients were non-vegetarian. Most common seizure type was generalised tonic clonic seizures (68\%) followed by simple partial seizures (12\%), complex partial seizure (10\%), myoclonic seizures (5\%) and absence seizures (4\%). Sleep deprivation was most common precipitating factor [Figure 2]. Postictal confusion (78\%), loss of consciousness $(62 \%)$ and retrograde anaemia (32\%) were reported by patients following seizures. Cause of seizure was idiopathic in $64 \%$ patients, while it was secondary to some underlying disease in 36\% patients. Most common cause of secondary seizures was neurocysticercosis $(14 \%)$ followed by head injury (5.6\%) and birth asphyxia in childhood (5.1\%). CNS infection (4.5\%), metabolic disorder $(2.8 \%)$ and brain tumour $(1.7 \%)$ were other cause of seizure [Table 4]. Among associated conditions, diabetes was found in 2 cases and hypertension in 6 cases. Human immunodeficiency virus infection was found in one case. Mental retardation was found in 6 cases. All of them had history of birth asphyxia. Behavioural disturbance in the form of anxiety and depression was found in 12 cases.

Eighty five percent were treated with single antiepileptic drug. Polytherapy was required from the beginning in 15\% of patients. Sodium valproate (69\%), phenytoin (35\%), carbamazepine $(29 \%)$, clobazam $(21 \%)$ and phenobarbitone $(10 \%)$ were used either alone or in combination.

Non-compliance for drug therapy was seen in 49 patients (28\%). Majority of them were illiterate $(57 \%)$ and from rural background (73\%). All of them were from poor socioeconomic status. Among non-compliant persons, 25 patients felt that it was not necessary to take medicine as their seizures were controlled, other skipped their drugs due to non-availability or uncomfortable side effects.

\begin{tabular}{|c|c|c|c|}
\hline Age (Years) & Male (\%) & Female (\%) & Total (\%) \\
\hline $0-4$ & $23(69.6)$ & $10(30.3)$ & $33(18.7)$ \\
\hline $5-14$ & $18(48.6)$ & $19(51.3)$ & $37(21.0)$ \\
\hline $15-44$ & $34(44.7)$ & $42(55.7)$ & $76(43.1)$ \\
\hline$>45$ & $22(73.3)$ & $8(26.6)$ & $30(17.0)$ \\
\hline Total & $97(55)$ & $79(44.8)$ & 176 \\
\hline
\end{tabular}

\begin{tabular}{|c|c|c|c|}
\hline $\begin{array}{c}\text { Age of } \\
\text { Onset }\end{array}$ & $\begin{array}{c}\text { Generalised } \\
\text { Seizure }\end{array}$ & $\begin{array}{l}\text { Partial } \\
\text { Seizure }\end{array}$ & $\begin{array}{c}\text { Total } \\
(\%)\end{array}$ \\
\hline $0-5$ & 29 & 8 & $37(21)$ \\
\hline $5-15$ & 31 & 10 & $41(23)$ \\
\hline $15-34$ & 41 & 11 & $52(30)$ \\
\hline$>35$ & 37 & 9 & $46(26)$ \\
\hline Total & 138 & 38 & 176 \\
\hline
\end{tabular}

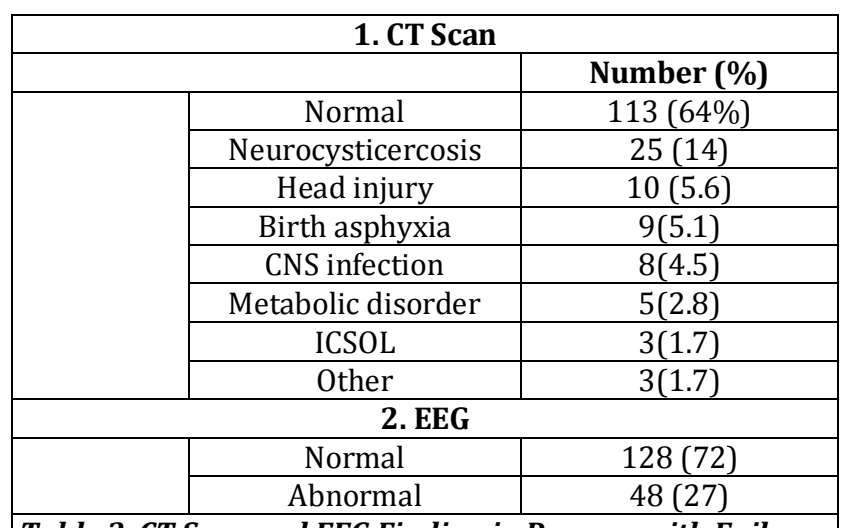

Table 3. CT Scan and EEG Finding in Persons with Epilepsy

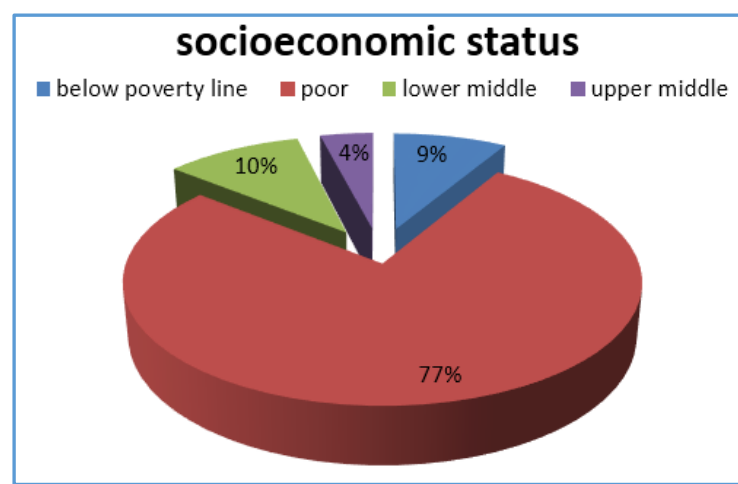

Figure 1. Socioeconomic Status of Persons with Epilepsy

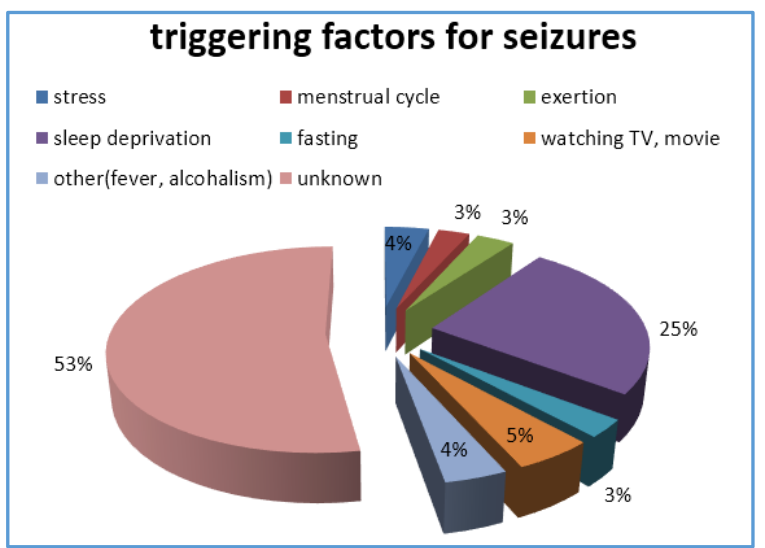

Figure 2. Triggering Factors for Seizures in Persons with Epilepsy 


\section{DISCUSSION}

Epilepsy is an important public health problem in Bundelkhand region. Understanding demographic and clinical profile of epilepsy at tertiary care setting would guide us to improve preventive measures and strengthening of service towards this condition. In our study, it is seen that that age specific prevalence rate was higher in younger age group (mean age 17.4 \pm .4 years) with the onset of epileptic seizure, reported mostly in first three decades of life. These findings were comparable to earlier studies carried out by Sridharan $\mathrm{R}^{(4)}$ and Avvaru KV et al.(10) In a study carried out in North-West India(11) it is found that males are more often involved than female and high proportion of cases are from lower socioeconomic status (62.8\%), finding being similar to our observation. As younger age group and people of poor socio-economic group are more affected by this condition, economic deprivation in the family could be more grievous. Family history of epilepsy was found in $20 \%$ of Sudanese epileptic patients,(12) which were more than our observation. In western countries, partial seizures were more common than generalised seizures.(13,14) Similar trend has been shown in some developing countries like Nigeria.(15) On the contrary reverse trend has been reported in Indian studies, where generalised seizures constitute more than $70 \%$ of all cases.(16) In the present study most common type of seizure was generalised tonic-clonic seizure (68\%), the finding being similar to earlier studies carried out in Pakistan(17) and South India.(18) Neurocysticercosis is the most common parasitic infection of brain and a leading cause of epilepsy in developing world. Murty et al(19) found that $10.4 \%$ cases had evidence of Neurocysticercosis, which is similar to our finding. A study done in Jaipur(11) and Sudan(12) found that EEG was abnormal in $58.9 \%$ and $64.8 \%$ respectively, which was higher than our finding. CT scan head was abnormal in $35 \%$ of cases in Jaipur study, which is similar to our finding. Low catchment of epileptic foci from EEG in patients with single unprovoked seizure underscores the importance of precise history and imaging (CT or MRI) for proper diagnosis of illness.

Monotherapy treatment regimen was used in 70\% - 90\% of patients in different studies,(11,20) which were similar to our observation. Single drug approach is more preferred as polytherapy exposes the patients to unnecessary side effects, drug interactions, complications and higher cost. In a study from Burdhwan,(20) it is seen that the patients on monotherapy were more compliant (95.3\%) than polytherapy. In our study sodium valproate (54\%) was the most commonly used antiepileptic drug, as it was easily available in hospital pharmacy and also most preferred AED worldwide.

Adherence to medication is crucial in preventing or minimising seizures and their cumulative impact on everyday life.(21) Non-adherence to antiepileptic drugs (AEDs) can result in breakthrough seizures. Non-compliance rate $(28 \%)$ was significantly higher in our study, as majority of patients were illiterate and from rural background where lot of stigma and false belief prevails.(5) In a study from Burdhwan,(20) noncompliance rate was only $12.7 \%$. This observation indicates the need to strengthen the public awareness programme to educate people about importance of adherence to AED even during periods of normality to avoid recurrent attacks. In a study from Pakistan(9) it was found that multidrug therapy, long treatment duration and elderly age were major reasons of non-compliance.

Since this is a hospital-based study, the finding may not indicate the true pattern of seizures in this geographic area. However, this is the only tertiary care hospital of Bundelkhand region which caters for the whole of adjacent population. The seizures scenario of most cases of this region might have been reflected in findings of this study.

\section{CONCLUSION}

This study gives valuable information on clinical and demographic characteristics of PWE living in Bundelkhand region of Central India. In view of the above finding the current study recommends that proper diagnostic technique, supervision and follow-up of PWE along with targeted and effective educational activity about epilepsy are critical parameters required for improvement of life quality of this group.

\section{REFERENCES}

[1] WHO neurological disorder: Public Health challenges. Geneva: World Health Organization, 2006.

[2] Santosh SN, Sinha S, Satishchandra P. Epilespy: Indian perspective. Ann Indian Acad Neurol 2014;17(Suppl1):S3-S11.

[3] Joseph N, Kumar GS, Nellyanil M. Pattern of seizures cases in tertiary care hospital in Karnataka state of India. Ann Indian Acad Neurol 2013;16(3):347-51.

[4] Sridharan R, Murthy BN. Prevalance and pattern of epilepsy in India. Epilepsia 1999;40(5):631-6.

[5] en.wikipedia.org. Wikipedia foundation inc 2015. http://.en.wikipedia.org/wiki/bundelkhand.

[6] Kankane AK, Kankane A, Siddiqui MZ, et al. Knowledge attitude and practice of epilepsy among persons attending tertiary care hospital of Bundelkhand region, Central India. Indian J Comm Health 2015;27(2):281-5.

[7] Agarwal A. Social classification: the need to update in the present scenario. Indian $\mathrm{J}$ Community Med 2008;33(1):50-1.

[8] Berg AT, Millichap JJ. The 2010 revised classification of seizures and epilepsy. Continuum (Minneap Minn) 2013;19(3 Epilepsy):571-97.

[9] Bano S, Numanb A. Factors influencing antiepileptic drug non-compliance in epileptic patients of Pakistan Pakistan J Neurol Sciences 2016;11(1):20-3.

[10] Avvaru KV, Seepana M, Kotamarthy HB. Int J Biol Med Res 2012;3(4):2523-6.

[11] Panagariya A, Surekha RK, Sharma B, et al. Clinical profile of epilepsy in tertiary care center of north-west India. J Indian Med Assoc 2011;109(1):14-8.

[12] Hussain A, Eltanir A, Yasin F, et al. Clinical presentation of epilepsy among adult Sudanese epileptic patients seen in Sheik Mohamed Kheirs Friday epileptic clinic - Sudan. Sudan J Med Sci 2007;2(1):21-3.

[13] Juul-Jenson P. Epidemiology of intractable epilepsy. In: Schmidt D, Morselli PL. eds. Intractable epilepsy. LERS monograph series, Vol. 5. New York: Raven Press 1986:5-12.

[14] Hauser WA. Epidemiology of epilepsy. World Neurology 2000;15(1):6-8. 
[15] Danesi MA, Odusote KA, Roberts O0, et al. Social problems of adolescent and adult epileptics in a developing country, as seen in Lagos, Nigeria. Epilepsia 1981;22(6):689-96.

[16] Pal SK, Sharma K, Prabhakar S, et al. Neuroepidemiology of epilepsy in northwest India. Annals of neurosciences 2010;17(4):160-6.

[17] Usman S, Chaudhary HR, Asif A, et al. Demographic profile of patients with epilepsy in a community clinic. Pak Med Sci 2007;23(6):873-6.

[18] Radhakrishnan K, Pandian JD, SantoshKumar T, et al. Prevalence knowledge attitude and practice of epilepsy in Kerala, south India. Epilepsia 2000;41(8):1027-35.
[19] Murty JM, Yangala R, Srinivas M. The syndromic classification of the International league against epilepsy: a hospital based study from south India. Epilepsia 1998;39(1):48-54.

[20] Sil A, Das K, Das NK, et al. Use of antiepileptic drug in tertiary care hospital of eastern India with emphasis on epilepsy due to neurocysticercosis. Indian J Pharmacol 2012;44(1):106-10.

[21] Baker GA, Jacoby A, Buck D, et al. Quality of life of people with epilepsy: a European study. Epilepsia 1997;38(3):353-62. 